Teaching \& Learning (2013) 7(3), 62-75

\title{
Gay-Straight Alliances: Making Ontario Schools Safe and Inclusive
}

\author{
JULIAN KITCHEN \\ Brock University \\ CHRISTINE BELLINI \\ Ontario Institute for Studies in Education \\ University of Toronto
}

\begin{abstract}
Gay-straight alliances (GSAs) have become widespread in Ontario schools and, starting in 2012, all schools are required to permit students to form GSAs. While American research suggests that GSAs have a positive impact on school safety and inclusion, there is little research on the impact of GSAs in Ontario schools. This study, based on a survey of 30 educators working with GSAs, suggests that policy changes in Ontario have had a positive impact on school climate for lesbian, gay, bisexual, transgender, and queer (LGBTQ) students, and that GSAs contribute to the development of safer and more inclusive schools. The next phase of the research will probe more deeply by increasing the number of respondents and conducting interviews with 14 participants.
\end{abstract}

\section{Introduction}

Gay-straight alliances (GSAs) have become a topic of much discussion in Ontario. The debate on Bill 13: Accepting Schools Act, (Ontario Ministry of Education [OME], 2012) passed in June 2012, revealed that the Ontario educational landscape has changed considerably since GSAs first appeared in the 1980s. Rayside (2008) found that only 1\% of schools had such groups, but there are now hundreds in secondary schools. The number and size are likely to grow now that the provincial government has identified the formation of GSAs an effective means of supporting sexual minority students in schools. This is reflected in its equity and inclusion policy (OME, 2009a), Bill 157 (OME, 2009b), which encouraged the formation of GSAs in secondary schools, and Bill 13, which requires all publicly funded secondary schools (public and Catholic) to allow students to form GSAs.

While American research suggests that GSAs have a positive impact, there is little evidence of the impact of GSAs in Ontario schools. Our current, ongoing research, "Gay-Straight Alliances and Homophobic Bullying in Ontario Schools: Perspectives of Educators Working 
with GSAs" offers the perspectives of GSA advisors on this issue. The first stage of the study involves an on-line survey of 40 to 60 GSA advisors; during the second stage, 14 survey participants will be interviewed.

The survey responses offer a window into the composition of GSAs, their activities, and the role of advisors. The educators serving as GSA advisors strongly endorse the view that GSAs and policies that promote the formation of GSAs make a positive difference for students of all sexual orientations and gender identities. Our preliminary findings suggest that recent policy changes have had a positive impact on school climate for lesbian, gay, bisexual, transgender, and queer (LGBTQ) students, and GSAs have had a positive impact on school safety and inclusion. This paper will help educators better understand GSAs, and the ways in which they can contribute to equity, student engagement, and enhanced learning.

\section{Literature Review}

Gay-straight alliances are a response to the prevalence of homophobia in schools. In order to understand GSAs, we frame our work in relation to understandings of gendered harassment, bullying, and school climate.

"Harassment and bullying in schools are persistent, prevalent, and commonly misunderstood," writes Elizabeth Meyer (2009, p. 1), with those targeted for homophobic harassment identified as being at a higher risk of negative outcomes (Meyer, 2009). Meyer's (2009) distinction between gendered harassment and bullying is useful for this study. Gendered harassment is "any behaviour that acts to shape and police the boundaries between traditional gender norms" (Meyer, 2009, p. 1). Whereas harassment may be occasional and unintentional, bullying is defined as "behaviour that repeatedly and over time intentionally inflicts injury" (p. 2). There has been ample research for over a decade in both Canada and the United States that verifies LGBTQ students are at higher risk of committing suicide, due to homophobic bullying in schools (Center for Addiction and Mental Health, 2004; Science Daily, 2010; United States Department of Health and Safety, 2001).

Major efforts have been made by educators and society to enhance school safety and reduce bullying in North America. In Ontario, safe schools amendments to the Education Act and multiple Ministry of Education documents have addressed these issues (e.g., OME 2009a; 2009b; 2012). School boards, in response, have embraced policies and initiatives designed to 
improve school climate, including character education, restorative justice, and peer support programs. The fact that school climate remains a challenge for many sexual minority students, despite enhanced legislation and policies, reinforces the critical role that teachers and administrators have in successful anti-bullying initiatives (Colorosso, 2003; Safe Schools Action Team, 2005).

We also frame the work around research conducted on school climate and school ecologies. The research on school ecologies indicate that the climate of a school is often established by students, with prevailing adolescent attitudes determining what constitutes cool, and who is identified as a freak or as a geek (Milner, 2004). Correlating school ecology research with evidence contained in school climate surveys conducted by EGALE Canada (2011), and by the Gay Lesbian Straight Educators Network (GLSEN, 2007; 2009), it is evident that LGBTQ students are viewed as not conforming to the norms of masculinity and femininity prevalent among the adolescent elites in schools. This leads to poor self-esteem among LGBTQ youth, and higher incidents of harassment and bullying.

Homophobic harassment and bullying remain persistent issues in most school cultures. The Equality for Gays and Lesbians Everywhere (EGALE) (2011) report, The First National Climate Survey on Homophobia, Biphobia, and Transphobia in Canadian Schools, revealed staggering levels of homophobia in Canadian schools. Sixty-four percent of LGBTQ students did not feel safe in school (EGALE, 2011). Seventy percent of all students reported hearing "that's so gay" every day in school (EGALE, 2011). The 2009 national school climate survey from the Gay Lesbian Straight Educators Network (GLSEN) in the United States revealed similar results to the Canadian data. Eighty-eight percent of students heard "that's so gay" every day in American schools, 84\% were verbally harassed for being gay, and 61\% of LGBTQ students did not feel safe in schools (GLSEN, 2009). The high rates of homophobic comments and bullying, are of particular concern in schools when related to teen suicide. In Canada, the Center for Addiction and Mental Health (2004) reported that suicides related to homophobic bullying have been on the rise for the past decade. The suicide of Ottawa student Jamie Hubley in 2011 made this issue real for many parents, educators, and LGBTQ students (Boesveld, 2011).

Educators can make a positive difference, but only if they take the initiative to address the problem of harassment and homophobic bullying in their schools. Clearly they are not when $75 \%$ of Canadian LGBTQ students and $62 \%$ of American (LGBTQ) students stated that teachers 
and administrators did nothing to stop homophobic comments and bullying when it was reported (EGALE, 2011, p. 50; GLSEN, 2009, p. 3). More surprising, 58\% of straight students surveyed were upset because they witnessed teachers doing nothing to stop homophobic comments and bullying occurring in their presence (EGALE, 2011, p. 26).

While there is limited information on the impact of GSAs in Ontario, there is considerable evidence from the U.S. that such groups have a significant impact on school environments and on the experiences of LGBTQ youth (Lipkin, 1999; GLSEN, 2009; Rayside, 2008). There are also many resources available to support the development of GSAs (e.g., EGALE Canada Human Rights Trust, 2011, mygsanetwork.org, glsen.org, and glad.org).

Given educators' pivotal role in promoting an inclusive environment for LGBTQ students, educators who facilitate GSAs seem well positioned to observe and comment on the climate in their schools, and the degree to which it has changed in response to recent initiatives in Ontario schools.

\section{Method of Inquiry}

In order to examine GSA facilitators' views of their school climate and their assessments of harassment and bullying following the introduction of GSAs, a survey research design was chosen. EGALE hosts a website titled mygsa.ca, which includes an anonymous email address for the advisors for each listed GSA in Canada. Each advisor was sent an email inviting them to participate in an electronic survey. Examples of the questions in the on-line questionnaire include:

How would you rate the overall climate of your school?

How would you rate the school climate for LGBTQ students?

Is your GSA visible to the rest of the school through: posters, announcements, yearbook club photo, club days, orientation days, parent teacher night, conferences, club t-shirts, other (specify).

Recount one of your proudest moments as a GSA facilitator?

Recount one of your greatest challenges or distressing moments as a GSA facilitator? 
Most questions are supplemented with a 7-point Likert scale and space for comments, while others were open-ended.

The data in this paper come from the first 30 responses to the on-line survey; another 30 GSA advisors were surveyed later in 2012 (after school district ethics boards approved the research). The 30 original participants were educators working in Ontario public secondary schools. These educators are primarily teachers (26) — along with educational assistants (3), and a child and youth worker- who volunteer to facilitate GSAs in their schools.

In reviewing and analyzing the responses of the preliminary data - 30 GSA advisors from 30 schools in Ontario on homophobic harassment and bullying - we consider the impact of government initatives such as Bill 157 (OME, 2009b), and Equity and Inclusive Education in Ontario schools (OME, 2009a), and draw on two main theoretical frameworks. The first is Meyer's (2009) framework for distinguishing between gendered harassment and bullying. We also frame the work around research conducted on school climate and school ecologies.

For the data analysis, the research team borrowed tenets of grounded theory to provide "a procedure for developing categories of information, interconnecting the categories, building a 'story' that connects the categories, and ending with a discursive set of theoretical propositions" (Strauss \& Corbin, 1990, as cited in Creswell, 1998, p. 15). After the team compiled the data, the two researchers reviewed the results independently, to identify emerging patterns in the data, while considering individual responses. Anecdotal responses provided in the comment boxes were then analyzed through coding and categorizing of key idea units, as described by Creswell (2009). The idea units were then collapsed into categorical clusters and themes representing participants' perceptions. The two researchers independently reviewed the qualitative data before combining their categories, in order to identify key overall findings and broad themes. In presenting the findings, the overall pattern of response, together with supportive quotes that illustrate the themes identified through analysis of participants' anecdotal responses, are included.

\section{Findings}

The findings have been organized into three broad categories. First, the composition and activities of the GSAs is documented. The next section reports on GSA advisor perceptions of harassment and bullying. The final section reports on the impact of GSAs on school climate. 
Gay-Straight Alliances

\section{Gay-Straight Alliances in Action}

There has been much discussion of GSAs recently, yet most people know little about the composition and activities of GSAs in schools, let alone the contribution that their presence makes to the school environment. This section begins with descriptive information about the participants' GSAs and schools. This is followed by information on school climate and on the impact of GSAs on school climate for LGBTQ students.

The 30 GSA advisors, each from a different school, were predominately female (88\%) and straight (68\%), with $16 \%$ identifying as lesbian and $12 \%$ as gay. Over $20 \%$ of GSA advisors came from each of the following subject areas: special education, English, social science and the arts, with few from math, sciences, physical education, or business. About half had facilitated GSAs for five years or more, while the others were less experienced. All of them saw themselves as models for students and teachers, either as allies (68\%) or as LGBTQ (32\%). Seventy five percent viewed themselves as educational resources to students and teachers, as well as activists (75\%). This sense of activism led many to engage with students in challenging events at school or in the community. These included organizing a Day of Silence, conference and panel discussion, parent night activities, and HIV support. Many of these educators were also the main advocates for LGBTQ issues at school, and for students experiencing homophobic harassment or bullying.

While the 30 GSAs in this study varied considerably in size and composition, clear patterns did emerge. Sixty percent of the schools had student populations over 1200 . The number of members in clubs tended to be either in the 6-10 (36\%) or in the $11-19(40 \%)$ range. Membership in many clubs tended to vary over several years, but there was no clear pattern upwards or downwards. In most clubs $(80 \%)$, the vast majority of members were female, with the other clubs evenly divided by gender. While most GSAs did not ask students to self-identify, many GSA advisors were under the impression that many members are heterosexual. In half the GSAs, only a few students publicly self-identified as LGBTQ, with another $25 \%$ of the advisors indicating that they were not sure about their members' sexual orientation. Only $25 \%$ of GSA advisors indicated that their clubs were predominately LGBTQ. Most GSA advisors seemed cautious about students 'outing' themselves, with one commenting that "sexual orientation was not brought up," in order to make it a safe space. The tendency towards silence about sexual orientation in many GSAs suggests that there may still be considerable stigma associated with 
LGBTQ identification (Clarke \& MacDougall, 2012; Goodenow, Szalacha, \& Westheimer 2006; Conway \& Crawford-Fisher, 2007; Toomey, Ryan, Diaz, \& Russell, 2011).

Most GSAs were very active, meeting weekly or bi-weekly after school to engage in a range of activities. Ninety-five percent of clubs engaged in conversation, with both students and educators taking active roles in leading discussion. The activities of the clubs, beyond building a supportive and safe environment through conversation, tended towards educational activities for members (75\%), educational outreach at school (75\%), and advocacy events at school (85\%). Most GSA advisors viewed their clubs as highly visible in their schools. Announcements (95\%) and posters $(90 \%)$ were primary means of raising visibility in most schools. Sixty percent also organized educational conferences for students. The lower numbers that had yearbook photos (65\%), club days (60\%), orientation days (45\%), and parent-teacher night presentations (27\%), suggests a more modest presence in the general activities of school life. Three-quarters of the clubs established alliances with other GSAs, which seemed to offer direction and support.

\section{Harassment, Bullying and School Climate}

In recent years, there has been growing awareness among educators and the public about school climate, particularly the levels of harassment and bullying in schools. As homophobia has been correlated with much of this harassment and violence (EGALE 2011; GLSEN 2009), antihomophobia and inclusion initiatives have been linked to more positive school climate (OME, 2009a; 2009b; 2012). One of the reasons GSAs have been endorsed in government policy is that they are seen as effective vehicles for creating safe spaces for LGBTQ students, and reducing homophobic harassment and bullying in schools.

In order to identify the degree of homophobic harassment and bullying in schools, we asked participants to rate the overall climate, rate of teasing and harassment, and the amount of bullying in their schools. After each, we asked them to rate these again in relation to homophobia or LGBTQ students. Below is a summary of the ratings on seven-point Likert scales.

Seventy percent of respondents in this survey rated the overall climate of their schools as safe generally (5-7 rating), while 50\% rated their schools as safe for LGBTQ students. On the other hand, more respondents found schools unsafe for LGBTQ youth (40\%), than for the school population as a whole (13\%). When asked to rate the amount of teasing and verbal harassment of students, most GSA advisors in the study (56\%) rated this as high generally, with more 
respondents (59\%) reporting even higher levels of homophobic/transphobic harassment. Many respondents (43\%) rated bullying overall as high (1-3), with more (55\%) identifying homophobic/transphobic bullying as high. While the school climate results reported by GSA advisors were similar for the general school population and LGBTQ students, there were seven schools in which the climate was poorer for LGBTQ students.

Teachers were generally viewed by the GSA advisors in the study as effective in responding to teasing and verbal harassment (75\%), but this score slipped notably (62\%) for homophobic/transphobic harassment. Eighty percent of the respondents viewed the responses of principals, vice-principals, and guidance counsellors to teasing and verbal harassment to be effective. This percentage reduced slightly (76\%) for homophobic/transphobic harassment. Of particular note is the percentage ranked as highly effective in their response (38\% in both cases).

Based on a holistic review of the data, the perceived rates of teasing and verbal harassment were high in both cases, with no significant differences. Interestingly, while the rates of teasing and verbal harassment were similar, teachers were perceived to be less likely to respond effectively to homophobic and transphobic comments. On the other hand, principals, vice-principals, and guidance counsellors were generally perceived to be effective at addressing both. A closer statistical analysis, once the study of 60 educators has been completed, should lead to greater insights into these phenomena.

\section{Impact of GSAs on School Climate}

Most respondents (80\%) reported that the presence of GSAs had a positive impact on school climate for LGBTQ identified students. About half of the positive respondents were emphatic in their conviction that GSAs made a considerable difference. Among the anecdotal comments made by survey respondents were:

- I have asked that question many times and the students feel that the presence of the GSA provides a "normalizing" effect on the school community.

- Absolutely. There has been a lot of emphasis on teaching through activities and our bulletin board. All students realize that there is support for the LGBTQ community in our school. Through the acquisition of knowledge comes comfort and understanding. 
Gay-Straight Alliances

- We like to think so. It does, however, mean some students hear comments (when the words are read aloud on announcements) that other students might make. Still, the students ask to have the words read.

- Yes, we have had assemblies, days of silence, and other events that inform the school of LGBTQ issues.

- Yes, we have reports from ex-students that it has helped and that, even if the students did not come, they felt that it was important to know that it was there.

- We have a strong GSA that monitors school safety for all LGBTQ students in our school.

The presence of the GSA was also likely to have a greater impact if the administration and teachers made addressing of homophobia a priority in the school. GSA members and advisors often served as leaders in these efforts.

\section{Educational Significance}

The survey data collected at the half-way point of this study offers interesting insights into the nature and impact of GSAs in Ontario schools. In this section, we highlight several significant findings, and consider how we might probe more deeply into emerging questions in the interview stage of this project. As the literature in Canada and the United States focuses on GSAs themselves, with little information on the perceptions and roles of GSA advisors, this research explores territory that is largely uncharted. Once interviews in the second phase of the research have been conducted, we will be able to probe more deeply into the issues raised by participants.

\section{GSA Advisors and Membership}

It is noteworthy that a majority of advisors and members were straight females. Many participants reported being questioned by colleagues, either overtly or covertly, about their sexual orientation. While the majority of male participants identified as gay, many did not disclose this to their peers or students. The stigma related to being identified as an LGBTQ educator is consistent with literature that finds homophobia still prevalent in schools (Wright, 2010). GSA advisors viewed themselves as being more of an activist than their colleagues. They defined their roles as advocates who were knowledgeable in the area of LGBTQ rights, school 
policies on bullying, and the Canadian Charter of Rights and Freedoms. Many discussed a need to advocate on behalf of GSA students when issues of bullying arose in school.

Most GSA advisors seemed cautious about students 'outing' themselves, with one commenting that "sexual orientation was not brought up," in order to make it a safe space. The tendency towards silence about sexual orientation in many GSAs suggests that there is still considerable stigma associated with LGBTQ identification (Toomey, Ryan, Diaz, \& Russell, 2011). While membership in GSAs did not carry a stigma in most cases, this could be because a significant number of female members were perceived to be allies rather than lesbian. The reasons for silence about sexual orientation will be explored in the interview stage of the project.

\section{Significance of GSA Activities}

The findings indicated that most of the activities that GSAs participated in centered on political action and awareness, and social events. These data are important to highlight, since they dispel some of the common myths in the media that state GSAs are often coming-out or counselling groups.

Many events centered on educating the entire school about homophobia. This suggests that students educating students may have more impact on school climate, than teachers in a classroom. There are several issues that complicate the success of addressing social justice issues in curriculum. Often teachers in our study stated that they do not know enough about LGBTQ issues to properly address them in class, and that in some schools the only course where LGBTQ issues were discussed was Health. If GSA activities take place during school hours, and attempt to advocate and educate, then there is a greater chance of success, due to their ability to reach more students, and to discuss issues on a peer level. The survey results identify a strong pattern of activism among GSAs, which needs to be explored more deeply in future conversations with advisors.

\section{School climate for LGBTQ students}

The survey data collected from respondents, and the comments accompanying the rankings, suggests that the climate in Ontario is reasonably safe for most students, including LGBTQ students. Nonetheless, schools are clearly less safe for students who are victimized by homophobic teasing, harassment, and bullying. 
While GSAs seem to contribute to improved school climate, another important factor seems to be increased vigilance by educators, particularly school administrators. Administrators may receive some training in the Principal's Qualification Course, in the form of policy and procedures related to bullying. The Ontario College of Teachers (2010) approved a new Additional Qualification course in LGBTQ Issues in Education, and the Ontario Secondary School Teachers Federation (2012) also runs anti-homophobia training every year. Other than these two venues, administrators would have to seek out their own professional development.

Given that many GSAs have been in existence less than five years - and advisors in long-standing clubs reported substantial improvements - a major factor would appear to be changes in education policy and law in Ontario. The Ministry of Education initiated several policies and procedures related to school climate homophobic bullying. Ontario's Equity and Inclusive Education Strategy (2009a), Bill 157 (2009b), and supporting policy and program memorandum, created a framework and timeline geared towards full implementation in 2010. In light of these policy changes, along with professional development and board directives, many administrators now take homophobia and bullying very seriously.

While GSA advisors were highly aware of these policies and their initial implementation, their comments about colleagues suggest that teachers remain inconsistent in their response to homophobic bullying and the reporting of incidents. The vigilance of GSA advisors is not always matched by their colleagues, or by all administrators. The contrast between GSA advisors and administrators suggests that more needs to be done to convert policy into teacher practice. This could be done through initial teacher preparation and ongoing professional development on sexual diversity and teachers' legal obligations (Kitchen \& Bellini, 2012). As Bellini (2012) has observed, Canadian teachers receive minimal, if any training on how to work with LGBTQ students.

\section{Conclusion}

Gay-straight alliances have become an important part of Ontario schools, thanks to the work of GSAs in schools, and the decision of the Ontario government to make them a critical component of its inclusion and safe schools policies. This research provides a glimpse into the membership and activities of GSAs in public schools, a preliminary sense of their contribution to making schools safe for sexual minority students, and the role GSA advisors play in making 
these changes happen. This research suggests that Ontario schools are becoming safer places for LGBTQ students. It appears that both the presence of gay-straight alliances in schools and the implementation of progressive provincial policies are factors in this development. While more research is needed to determine the relationship between these factors, it is likely a dynamic relationship in which the grassroots emergence of GSAs encouraged the government to incorporate them into its safe schools and inclusive education policies, which has then led to an increase in both GSAs and school safety (GSLEN, 2009; EGALE, 2011). While American research indicates that GSAs have a positive impact, this study may offer significant insights into how school climate for LGBTQ students can improve, when the work of GSAs is systematically supported by government policy and educators in schools. As we continue to collect survey data and supplement it with interviews, we will develop a better understanding of the impact of GSAs in Ontario.

Acknowledgements

This research is supported by a Dean's Research Initiative grant by the Dean of Education, Brock University.

Julian Kitchen is a professor in the Faculty of Education at Brock University. In addition to his research in teacher education and Aboriginal education, he has conducted numerous workshops on LGBTQ issues for Brock students.

Christine Bellini is a part time doctoral student at OISE/University of Toronto. She is a full-time secondary school teacher, and has been a GSA Advisor for the past six years. Her Master's thesis focused on LGBTQ teens and teacher education.

\section{References}

Bellini, C. (2012). The pink lesson plan: Addressing the emotional needs of gay and lesbian students in teacher education. Journal of LGBT Youth, 9(4).

Boesveld, S. (2011, April 17). "This hurts too much" gay teen says in last blog before suicide. The National Post.

Center for Addiction and Mental Health. (2004). Better dead than queer. CrossCurrents: The Journal of Addiction and Mental Health, Winter.

Clarke, P. \& MacDougall, B. (2012). The case for gay straight alliances (GSAs) in Canada's public schools: An educational perspective. Education \& Law Journal, 21, 143-165.

Colorosso, B. (2003). The bully, the bullied and the bystander: From preschool to high schoolhow parents and teachers can help break the cycle of violence. New York, NY: Harper Collins.

Conway, T. R., \& Crawford-Fisher, R. (2007). The need for continued research on gay straight alliances. Journal of Curriculum and Pedagogy, 4(2), 125-129. 
Creswell, J. W. (1998). Qualitative inquiry and research design: Choosing among five traditions. Thousand Oaks, CA: Sage.

Creswell, J. W. (2009). Research design: Qualitative, quantitative, and mixed method approaches $\left(3^{\text {rd }}\right.$ ed.). Thousand Oaks, CA: Sage.

EGALE Canada Human Rights Trust. (2011). Mygsa.ca: Equity and inclusive education resource kit for Ontario high schools. Toronto, ON: Author.

Equality for Gays and Lesbians Everywhere (EGALE). (2011). Every class in every school: The final report on the first national climate survey on homophobia, biphobia, and transphobia in Canadian schools. Retrieved from http://www.egale.ca

Gay and Lesbian Alliance Against Defamation. (2012). Resources and programs. Retrieved from http://www.glaad.org/resources

Gay Lesbian Straight Educators Network. (2007). The 2007 national school climate survey. Retrieved from http://www.glsen.org/cgi-bin/iowa/all/news/record/2340.html

Gay Lesbian Straight Educators Network. (2009). The 2009 national school climate survey. Retrieved from http://www.glsen.org/cgi-bin/iowa/all/news/record/2624.html

Goodenow, C., Szalacha, L., \& Westheimer, K. (2006). School support groups, other school factors, and the safety of sexual minority adolescents. Psychology in the Schools, 43(5), 573-589.

Kitchen, J., \& Bellini, C. (2012). Addressing lesbian, gay, bisexual, transgender and queer (LGBTQ) issues in teacher education: Teacher candidates' perspectives. Alberta Journal of Educational Research, 58(3), 444-460.

Lipkin, A. (1999). Understanding homosexuality, changing schools. Boulder, CO: Westview Press.

Meyer, E. J. (2009). Gender, bullying and harassment. New York, NY: Teachers College Press.

Milner, Jr., M. (2004). Freaks, geeks and cool kids: American teenagers, schools and the culture of consumption. New York, NY: Routledge.

My GSA Network. (2012). Website. Retrieved from http://www.gsanetwork.org

Ontario College of Teachers. (2010). Retrieved from http://www.oct.ca/ /media/PDF/Additional\%20Qualification\%20Consultation $\% 20$ on $\% 2$ 0Teaching\%20LGBTQ/aq consultation_e.ashx

Ontario Ministry of Education. (2009a). Equity and inclusive education in Ontario schools: Guidelines for policy development and implementation, realizing the promise of diversity.

Ontario Ministry of Education (2009b). Bill 157: Education Act Amendment (Keeping Our Kids Safe at School). S.O. 2009, c. 17.

Ontario Ministry of Education (2012). Bill 13: Education Act Amendment (Accepting Schools). S.O. 2009 , c. 13.

Ontario Ministry of Education. (2012, June 19). Education Act, R.S.O. 1190, c.E.2, Section 13: Behavior Discipline and Safety, Articles 303.1, 303.2, 303.3.

Ontario Secondary School Teachers Federation. (2012). Educational services workshops. Retrieved from http://www.osstf.on.ca/edservicesworkshops

Rayside, D. (2008). Queer inclusions, continental divisions: Public recognition of sexual diversity in Canada and the United States. Toronto, ON: University of Toronto Press.

Safe Schools Action Team. (2008). Shaping a culture of respect in our schools: Promoting safe and healthy relationships. Toronto, ON: Ontario Ministry of Education.

Science Daily. (2010, February 10). Youth who self-identify as gay, lesbian or bisexual at higher 
suicide risk. Science Daily. Retrieved from http://www.sciencedaily.com/releases/2010/02/100205122240.htm

Toomey, R. B., Ryan, C., Diaz, R. M., \& Russell, S. T. (2011). High school gay straight alliances (GSAs) and young adult well being: An examination of GSA presence, participation, and perceived effectiveness. Applied Developmental Science, 15(4), 175-185.

United States Department of Health Control and Center for Disease Control. (2001, December 7). School health guidelines to prevent unintentional injuries and violence. Retrieved from http://www.cdc.gov/mmwr/preview/mmwrhtml/rr5022a1.htm

Wright, T. (2010). LGBTQ educator's perceptions of school climate. Phi Delta Kappan, 91(8), 49-53. 